\title{
Geographical knowledge in patients with Parkinson's disease
}

\author{
WILLIAM W. BEATTY and NANCY MONSON \\ The Neuropsychiatric Institute, Fargo, North Dakota \\ and North Dakota State University, Fargo, North Dakota
}

\begin{abstract}
Geographical knowledge in patients with Parkinson's disease was studied with the revised version of the Fargo Map Test (Beatty, 1988). Patients with Parkinson's disease who scored within the range of normal controls on a standard clinical mental status exam were impaired in locating US cities, but otherwise they performed normally. Patients who scored below the control range on the mental status test were impaired in locating US cities, regional cities, and gross features of US geography, as well as in naming the states in which the US cities are located. Patients with Parkinson's disease appear to suffer retrograde amnesia with respect to visuospatial (geographical) knowledge as well as other forms of information.
\end{abstract}

When required to identify famous persons from photographs or to recall current events, some patients with Parkinson's disease exhibit retrograde amnesia that is equally severe with respect to information acquired premorbidly in both the distant and the recent past (Freedman, Riviora, Butters, Sax, \& Feldman, 1984; Huber, Shuttleworth, \& Paulson, 1986). These deficits in remote memory are observed only in patients with Parkinson's disease whose overall mental status is below the range for normal controls.

Recently, using geographical information as an index, we devised a method of measuring remote memory of visuospatial information (Beatty, 1988). With this technique, we have observed impairments in patients with chronic progressive multiple sclerosis (Beatty, Goodkin, Monson, Beatty, \& Hertsgaard, 1988) and Huntington's disease (Beatty, 1985). Since the profiles of neuropsychological deficits that accompany multiple sclerosis, Huntington's disease, and Parkinson's disease are quite similar (Cummings \& Benson, 1984; Rao, 1986), we predicted that patients with Parkinson's disease would exhibit impairments on tests of geographical knowledge.

\section{METHOD}

\section{Subjects}

The subjects were 42 patients with idiopathic Parkinson's disease, who were referred to us by area neurologists. To be accepted into the study, patients had to exhibit at least two of the following signs: masked facies, tremor at rest, cogwheel rigidity, bradykinesia, and disturbances of postural reflexes. They also had to have shown improvement in their neurological symptoms following treatment with dopaminergic medication. Patients with a history of drug or alcohol abuse, other central nervous system diseases, or major psychiatric illness were excluded.

We thank Charles Anderson, Richard Bailly, Randall Bjork, Donald Goodkin, Ryan Harrington, Robert Ivers, and William Weir for allowing us to test their patients. Address reprint requests to: William W. Beatty, Department of Psychology, North Dakota State University, Fargo, ND 58105.
No patient had undergone a neurosurgical procedure. At the time of testing, all but one of the patients were receiving dopaminergic and/or anticholinergic medications, with doses adjusted for optimal clinical benefit. All the patients provided written informed consent.

\section{Materials and Procedures}

All the patients received the following tests: the Mini-Mental State Exam (MMSE; Folstein, Folstein, \& McHugh, 1975), the Line Orientation Test (Benton, Hamsher, Varney, \& Spreen, 1983), and the revised version of the Fargo Map Test (FMT-R; Beatty, 1988). The FMT-R requires subjects to locate 10 gross features of US geography, 30 US cities, and 18 cities in the tristate region (ND-SD-MN) on outline maps. In addition, the patients named the state in which each of the 30 US cities was located (termed here city-state) and indicated which of the 48 contiguous US states and 18 tristate cities they had visited or through which they had traveled on surface transportation at any time during their lives.

On the basis of their performances on the MMSE, the patients were divided into normal MMSE $(N=25$; MMSE score: $28-30)$ or low MMSE ( $N=17$; MMSE score: $22-27)$ subgroups. The patients in the normal MMSE group averaged 64.1 years of age, 13.6 years of education, and 23.5 on the Line Orientation Test. The patients in the low MMSE group averaged 68.4 years of age, 10.8 years of education, and 20.4 on the Line Orientation Test. Significant $(p<.01)$ differences were observed between the two MMSE subgroups in education and performance on the Line Orientation Test, but not in age. On the Line Orientation Test, 6 patients in the low MMSE subgroup and 3 patients in the normal MMSE subgroup scored in the clinically impaired range.

\section{Data Analysis}

Performance on the FMT-R is influenced by gender, age, education, and travel experience (Beatty, 1989; Beatty \& Troster, 1987). To control for these variables, each patient's score on each of the dependent variables was expressed as a $Z$ score, calculated with respect to the performance of normal residents of the area of the same gender and age, with the same educational level (Beatty, 1989). Comparisons of the performance of patients with Parkinson's disease to the performance of normal controls were made with single-sample $t$ tests. ANOVAs were employed to compare the performances of the two patient subgroups.

\section{RESULTS}

The performances of the two subgroups of patients with Parkinson's disease are summarized in Table 1. Here it can be seen that, relative to normal controls, the patients 
Table 1

Performance of Patients with Parkinson's Disease on Measures of Geographical Knowledge and Extent of Travel

\begin{tabular}{lccccc}
\hline & \multicolumn{2}{c}{ Normal MMSE } & & \multicolumn{2}{c}{ Low MMSE } \\
\cline { 2 - 3 } \cline { 5 - 6 } & $M$ & $S E M$ & & $M$ & $S E M$ \\
\hline Gross features of US geography & -0.73 & .36 & & -1.23 & $.43 *$ \\
Locating US cities & -0.79 & $.20 \ddagger$ & & -1.12 & $.23 \ddagger$ \\
City-state & -0.30 & .28 & & -6.61 & $2.89 *$ \\
Locating tristate cities & 0.04 & .19 & & -1.14 & $.32 \dagger$ \\
States visited & -0.36 & .25 & & -0.39 & $.18^{*}$ \\
Tristate cities visited & 0.36 & .18 & & 0.02 & .32 \\
\hline
\end{tabular}

Note-MMSE = Mini-Mental State Exam. Values reported are mean $(S E M) Z$ scores, computed with respect to local norms for normal subjects (Beatty, 1989). $\quad{ }^{*} p<.05 . \quad \dagger p<.01 . \quad \neq p<.001$.

in the normal MMSE subgroup were impaired only in locating US cities (most of which were outside their home region). In contrast, in comparison with the normal controls, the patients in the low MMSE subgroup were impaired on all three of the visuospatial measures of geographical knowledge, as well as on the verbal measure (city-state).

The patients in the low MMSE subgroup had visited fewer US states than is typical for normal residents of this region, but they had visited a normal number of tristate cities. The travel experiences of the patients in the normal MMSE subgroup were not significantly different from those of the controls.

Differences between the two patient subgroups were significant for locating tristate cities $[F(1,40)=12.07, p<$ $.01]$ and for naming the state in which each of the $30 \mathrm{US}$ cities is located $[F(1,40)=6.93, p<.05]$. On other variables, the two subgroups did not differ significantly $(F \mathrm{~s}<1.18)$.

\section{DISCUSSION}

Previous studies (Freedman et al., 1984; Huber et al., 1986) have reported retrograde amnesia in patients with Parkinson's disease who have lower than normal mental status, but not in patients with normal mental status. Consistently with those earlier results, we observed significant impairments on all measures of geographical knowledge in the patients in the low MMSE subgroup. We also observed a deficit on one measure of geographical knowledge in patients with Parkinson's disease who had normal mental status, which was unlike the result of previous studies.

The impairments in locating US cities exhibited by the patients in the normal MMSE subgroup cannot be attributed to limited travel experience or to defective visuospatial perception, since these patients had visited about as many US states as had the normal controls, and they performed normally on the Line Orientation Test. Tentatively, we conclude that these patients exhibit retrograde amnesia with respect to visuospatial information, as it is reflected in loss of geographical knowledge.

The broad range of deficits displayed by patients with Parkinson's disease who have lower than normal mental status is more difficult to interpret. Limited travel experience may have contributed to their difficulties in identifying features of US geography outside of their home region, but travel experience cannot explain their inability to locate cities in the tristate region accurately. Deficits in visuospatial perception, as indexed by impairments on the Line Orientation Test, could help to explain the poor performance of the patients in the low MMSE subgroup on the three visuospatial measures of geographical knowledge. It is unlikely, however, that problems in visuospatial perception contributed to their deficits on the verbal measure of geographical knowledge (i.e., city-state). Since the vast majority of normal subjects over the age of 40 score at ceiling on this measure, the patients' impairments probably reflect a genuine defect in remote memory. Elsewhere, we (Beatty, Staton, Weir, Monson, \& Whitaker, 1989) describe global cognitive disturbances in patients with Parkinson's disease who have lower than normal mental status. It is likely that derangement of a number of cognitive functions, including remote memory, contributes to the poor performance of these patients on tests of geographical knowledge.

The impairments in geographical knowledge observed in patients with Parkinson's disease in the present study are qualitatively similar to earlier findings based on identical testing procedures for patients with multiple sclerosis (Beatty, et al., 1988). The deficits among the patients with Parkinson's, however, were quantitatively more severe. On a slightly different form of the FMT, patients with Huntington's disease also exhibited impairment (Beatty, 1985). Taken together, these observations suggest that retrograde amnesia with respect to visuospatial information as well as other types of premorbidly acquired knowledge may be a relatively common consequence of the subcortical dementias. On tests requiring identification of famous people or recall of past public events, the deficits in remote memory exhibited by patients with Huntington's disease, multiple sclerosis, and Parkinson's disease are equally severe with respect to information acquired in both the distant and the recent past (Albert, Butters, \& Brandt, 1981; Beatty, 1985; Beatty et al., 1988; Freedman et al., 1984; Huber et al., 1986). Whether or not a similar "flat" temporal gradient of retrograde amnesia with respect to geographical knowledge can be demonstrated in patients with Parkinson's disease remains to be determined.

\section{REFERENCES}

Albert, M. S., Butters, N., \& Brandt, J. (1981). Patterns of remote memory in amnesic and demented patients. Archives of Neurology, 38, 495-500.

Beatty, W. W. (1985). Assessing remote memory for space: The Fargo Map Test. Journal of Clinical \& Experimental Neuropsychology, 7, 640. (Abstract)

BeatTy, W. W. (1988). The Fargo Map Test: A standardized method for assessing remote memory for visuospatial information. Journal of Clinical Psychology, 44, 61-67.

BeatTy, W. W. (1989). Geographical knowledge throughout the lifespan. Bulletin of the Psychonomic Society, 27, 379-381.

Beatty, W. W., Goodkin, D. E., Monson, N., Beatty, P. A., \& HerTSGAARD, D. (1988). Anterograde and retrograde amnesia in patients with chronic progressive multiple sclerosis. Archives of $\mathrm{Neu}$ rology, 45, 611-619.

Beatty, W. W., Staton, R. D., Weir, W. S., Monson, N., \& Whitaker, H. A. (1989). Cognitive disturbances in Parkinson's disease. Journal of Geriatric Psychiatry \& Neurology, 2, 22-33.

Beatty, W. W., \& Troster, A. I. (1987). Gender differences in geographical knowledge. Sex Roles, 16, 565-590.

Benton, A. L., Hamsher, K. De S., Varney, N. R., \& Spreen, O. 
(1983). Contributions to neuropsychological assessment: A clinical manual. New York: Oxford University Press.

Cummings, J. L., \& Benson, D. F. (1984). Subcortical dementia: Review of an emerging concept. Archives of Neurology, 41, 874-879.

Freedman, M., Riviora, P., Butters, N., SaX, D. S., \& Feldman, R. S. (1984). Retrograde amnesia in Parkinson's disease. Canadian Journal of Neurological Sciences, 11, 297-301.

Folstein, M. F., Folstein, S. E., \& McHugh, P. R. (1975). “MiniMental-State": A practical method for grading the cognitive state of patients for the clinician. Journal of Psychiatric Research, 12, 189-198.
Huber, S. J., Shuttleworth, E. C., \& Paulson, G. W. (1986). Dementia in Parkinson's disease. Archives of Neurology, 43, 987-990.

Rao, S. M. (1986). Neuropsychology of multiple sclerosis: A critical review. Journal of Clinical \& Experimental Neuropsychology, 8, 503-542.

(Manuscript received December 9, 1988.)

\title{
Announcement
}

\author{
International Congress of Psychology \\ Brussels, Belgium \\ July 19-24, 1992
}

The next International Congress of Psychology will be held in Brussels, July 19-24, 1992, under the auspices of the International Union of Psychological Science (IUPsyS).

Congress brochures may be obtained from Brussels International Conference Centre, Place des Expositions, Place de Belgique, B-1020 Brussels, Belgium (FAX 32247880 23).

Proposals for the Scientific Program, including symposia, may be sent to the U.S. member of IUPsyS, the National Academy of Science. They should be addressed to Pamela Ebert Flattau, USNC/IUPsyS, National Research Council, GH 186, 2101 Constitution Avenue, N.W., Washington, D.C. 20418. 